\title{
Tracheotomy: Airway Management, Communication and Swallowing, 2nd ed. Edited by Eugene N. Myers and Jonas T. Johnson
}

\author{
Plural Publishing, Inc., San Diego, CA, 2008, 238 pp, US \$125.00, \\ ISBN-13: 978-1-59756-101-3; ISBN-10: 59756-101-0
}

\author{
Donna C. Tippett
}

Published online: 25 October 2008

(C) Springer Science+Business Media, LLC 2008

Tracheotomy: Airway Management, Communication and Swallowing, 2nd ed. is a multi-authored textbook edited by Eugene N. Myers and Jonas T. Johnson. The contributors to the textbook represent the fields of anesthesiology, general surgery, internal medicine, laryngology, otolaryngology, oncologic nursing, and speech-language pathology. Several of the contributors are new with this edition. Like the first edition, the second edition is divided into three sections. The first section is "Airway Management." The chapter on tracheostomy in the intensive care unit is included here rather than in the "Rehabilitation" section as it was in the first edition. In the second section, "Special Considerations," tracheostomy in those with burns and obstructive sleep apnea are discussed. Tracheostomy in those with obesity and HIV are deleted from the second edition. In the third section, "Rehabilitation," nursing management, long-term care, communication options, and swallowing are covered as they were in the earlier edition.

The book begins with a chapter on "The History of Tracheostomy and Intubation," in which the history of airway management is addressed meticulously. The development of tracheotomy is chronicled from $3600 \mathrm{BC}$ to modern times. The evolution of intubation is traced from the 10th century. Indications for tracheotomy and intubation are also described.

Nonsurgical options to maintain the airway are discussed in Chapter 2. Alternatives include noninvasive

\section{C. Tippett $(\square)$}

Department of Otolaryngology—Head and Neck Surgery, Johns

Hopkins University, Baltimore, MD 21287, USA

e-mail: dtippet1@jhmi.edu

D. C. Tippett

Department of Physical Medicine and Rehabilitation, Johns

Hopkins University, Baltimore, MD 21287, USA positive pressure ventilation; laryngeal mask airway; oral, nasal, and submental intubation; extracorporeal membrane oxygenation; and high-frequency jet ventilation. Cricothyroidotomy, an invasive option, is described as well. Complications associated with all options are explained. This discussion of alternatives to tracheotomy rounds out the book's coverage of airway management options.

Complications of and indications for tracheostomy in adults are covered in Chapter 3. Surgical technique, postoperative care, and an algorithm for decannulation are detailed. Complications and, perhaps more importantly, prevention of complications are reviewed. Speech-language pathologists will appreciate the citations that support use of speaking valves in the restoration of swallowing function and the cautionary comments regarding cuff inflation. The authors comment that valving may improve swallowing. This is somewhat controversial [1-3], although other groups (those cited by the authors and [4]) found that valving reduces the incidence and severity of aspiration. In the discussion of vocal fold injection, collagen (e.g.,Cymetra) [5] is an option that is not mentioned.

As in the previous edition, the book is geared toward the care of adult patients. However, Chapter 4 is devoted to the preoperative care, surgical technique, postoperative care, and complications in the pediatric population. Differences in care between children and adults are highlighted. The sections on complications in Chapters 3 and 4 are somewhat reiterative.

Care of the individual with tracheostomy in the intensive care unit is thoroughly addressed in Chapter 5 . The text is supplemented with several helpful tables and figures. Endoscopic percutaneous dilatational tracheostomy is a recent addition to the options for airway management. Candidacy criteria, procedural details, and complications are reviewed. Aspects of patient care, including tracheostomy 
tube changes, cleaning, suctioning, feeding, and members of the care team are covered. Consequences associated with cuffs and infection in the individual with tracheostomy are explained.

Current options for selecting a tracheostomy tube, including pediatric tubes, specialty tubes, and the innovations of the oval tube and the bulge cuff, are presented in Chapter 6. This information is communicated clearly and enhanced with figures and tables.

Special populations, patients with burns and sleep apnea, are discussed in Chapters 7 and 8. These chapters are brief, but specify the preferred practice parameters of the authors.

In Chapter 9, valuable practical information is given. The need for patient education is identified. The author recommends cuff inflation during meals, which is not standard. The inflated cuff eliminates throat clear and cough as airway protection mechanisms. When the cuff is deflated and the cannula is occluded or valved, throat clearing and coughing can protect the airway from laryngeal penetration and aspiration, enhancing the potential for oral alimentation/hydration [6, 7].

In Chapter 10, population statistics are reported and the options for post-acute care, which is an aspect of tracheostomy care that receives less attention than the acute phase, are described. Long-term acute care hospitals, which are a newer option, are discussed. The need for wellwritten policies and procedures, personalized care plans, and an interdisciplinary team is identified. Useful sample policies are included. The importance of care-giver support and education, physician oversight of home-care plans, and communication among care providers are rightly emphasized as vital components of home care.

Communication and swallowing, which are often given limited attention in this population, are the focus of the final two chapters. In Chapter 11, implications for communication, airway protection, airway clearance, integrity of the trachea, and laryngeal structure and function associated with tracheostomy and cuff inflation are reviewed comprehensively. Cuff deflation and speaking valves are discussed in detail, including candidacy criteria and a placement protocol. Options to facilitate oral communication when cuff deflation is not possible, such as mouthing words, electrolarynges, fenestrated cannulas, and speaking trachs, are described. Nonoral options are also included. One addition to the discussion regarding oral communication in those requiring a mechanical ventilator is the work of Hoit and colleagues [8-10] and Prigent and colleagues [11]. In-line speaking valves may be used in combination with cuff deflation but are not required for successful ventilator-assisted oral communication [12]. Ventilator settings can be modified to optimize oral communication via cuff deflation. Hoit et al. [8-10] studied how ventilator modifications influence the quality of speech production. They recommended decreasing inspiratory flow and adding positive end-expiratory pressure. Prigent et al. [11] reported that speech production parameters are improved when bilevel positive pressure versus assist-control ventilator support is used.

Diagnosis and treatment of swallowing disorders are addressed in Chapter 12. The section on the preplanning stage of the assessment is organized in an effective question-and-answer format. The statement that ventilatordependent individuals usually require an inflated cuff seems to be an overgeneralization, as there are descriptions of several cases of successful cuff deflation in this patient population, particularly as patients become medically stable [8-11, 13-15]. The clinical assessment, including the utility and limitations of blue dye testing, is discussed. The sections on instrumental assessment and treatment are more general overviews rather than material specific to those with tracheostomy.

The editors brought together a diverse group of experts to produce a well-conceived and high-quality book. The management of individuals with tracheostomy is treated comprehensively, addressing surgical and nonsurgical airway management, and care from the intensive care unit through the post-acute phase. The broad scope of this book makes it a valuable resource for all of the members of the tracheostomy care team.

\section{References}

1. Leder SB. Effect of a one-way tracheostomy speaking valve on the incidence of aspiration in previously aspirating patients with tracheotomy. Dysphagia. 1999;14:73-7.

2. Leder SB, Ross DA, Burrell MI, Sasaki CT. Tracheotomy tube occlusion status and aspiration in early postsurgical head and neck cancer patients. Dysphagia. 1998;13:167-71.

3. Leder SB, Tarro JM, Burrell MI. Effect of occlusion of a tracheotomy tube on aspiration. Dysphagia. 1996;11:254-8.

4. Suiter DM, McCullough GH, Powell PW. Effects of cuff deflation and one-way tracheostomy speaking valve placement on swallow physiology. Dysphagia. 2003;18:284-92.

5. Morgan JE, Zraick RI, Griffin AW, Bowen TL, Johnson FL. Injection versus medialization laryngoplasty for the treatment of unilateral vocal fold paralysis. Laryngoscope. 2007;117:2068-74.

6. Siebens AA, Tippett DC, Kirby N, French J. Dysphagia and expiratory air flow. Dysphagia. 1993;8:266-9.

7. Tippett DC, Siebens AA. Using ventilators for speaking and swallowing. Dysphagia. 1991;6:94-9.

8. Hoit JD, Banzett RB. Simple adjustments can improve ventilatorsupported speech. Am J Speech Lang Pathol. 1997;6:87-96.

9. Hoit JD, Shea SA, Banzett RB. Speech production during mechanical ventilation in tracheostomized individuals. J Speech Hear Res. 1994;37:53-63.

10. Hoit JD, Banzettt RB, Lohmeier HL, Hixon TJ, Brown R. Clinical ventilator adjustments that improve speech. Chest. 2003; 124:1512-21. 
11. Prigent H, Samuel C, Louis B, Abinun MF, Zerah-Lancner F, Lejaille $\mathrm{M}$, et al. Comparative effects of two ventilatory modes on speech in tracheostomized neuromuscular patients. Am J Respir Crit Care Med. 2003;167:114-9.

12. Hoit JD, Banzett RB. Je peux parler! Am J Respir Crit Care Med. 2003;167:101-2.

13. Bach JR, Alba AS. Tracheostomy ventilation: a study of efficacy with deflated cuffs and cuffless tubes. Chest. 1990;97:679-83.

14. Passy V, Baydur A, Prentice W, Darnell-Neal R. Passy-Muir tracheostomy speaking valve on ventilator-dependent patients. Laryngoscope. 1993;103:653-8.
15. Tippett DC, Siebens AA. Preserving oral communication in individuals with tracheostomy and ventilator dependency. Am J Speech Lang Pathol. 1995;4:55.

Donna C. Tippett MPH, MA, CCC-SLP 